\title{
Experimental demonstration of variable weight SAC-OCDMA system for QoS differentiation
}

\begin{abstract}
In this paper the experimental and simulation results of variable-weight spectral amplitude coding optical code division multiple access (VW-SAC-OCDMA) system is demonstrated. In the proposed system, three users with weights of 6,4 and 2 each operating at data rate of 1.25 $\mathrm{Gb} / \mathrm{s}$ represent video, data and voice services, respectively. Results show that for back-toback system minimum average power of $-20 \mathrm{dBm}$ per chip is required to maintain the acceptable performance. Transmission up to $60 \mathrm{~km}$ of fiber is demonstrated. Using mathematical approximation the capacity of VW-SAC-OCDMA system is demonstrated.
\end{abstract}

Keyword: Variable weight code; Optical code division multiple access; QoS differentiation; Optical fiber communication 